\title{
EVALUASI PERKULIAHAN DARING KETERAMPILAN MENULIS SELAMA MASA PANDEMI COVID-19 DENGAN MODEL EVALUASI CIPP
}

\author{
Cahyo Hasanudin ${ }^{1}$, Wagiran ${ }^{2}$, Subyantoro ${ }^{3}$ \\ ${ }^{1}$ Fakultas Pendidikan Bahasa dan Seni, IKIP PGRI Bojonegoro \\ ${ }^{1}$ Mahasiswa S3 Ilmu Pendidikan Bahasa, Pascasarjana Universitas Negeri Semarang \\ 1email: cahyo.hasanudin@ikippgribojonegoro.ac.id \\ ${ }^{2,3}$ Ilmu Pendidikan Bahasa, Pascasarjana Universitas Negeri Semarang \\ 2email: wagiran@mail.unnes.ac.id \\ 3email: bintoro@mail.unnes.ac.id
}

\begin{abstract}
The evaluation of CIPP model is a very complete and comprehensive evaluation model in evaluating a program. This study aims to evaluate online learning for writing subject in the Indonesian Language and Literature Education Department, IKIP PGRI Bojonegoro during the covid-19 pandemic using CIPP evaluation model. This qualitative study is descriptive evaluative research. There are primary and secondary data. Technique in collecting data are interview, questionnaire, and documentation. This study utilizes an online learning evaluation instrument for writing subject using 21 questions and implementing very inappropriate criteria $(\leq 25 \%)$, not suitable criteria $(\geq 26 \%)$, appropriate criteria $(\geq 51 \%)$, and very suitable criteria $(\geq 76 \%)$. The data is analyzed using content analysis method. The results of study show that the evaluation of online learning on writing subject during the covid19 pandemic using CIPP evaluation model on the context aspect obtains $90 \%$. In the input aspect, the percentage is $82 \%$. In the process aspect, the percentage is $88 \%$. In the product aspect, the percentage is $92 \%$. The percentage is obtained from the average number of all indicators in each aspect. It can be concluded that online learning of writing subject during the covid-19 pandemic from all aspects (context, input, process, product) is very appropriate.
\end{abstract}

Keywords: CIPP evaluation model, online learning, writing subject, covid-19 pandemic

Abstrak: Evaluasi model CIPP merupakan model evaluasi yang sangat lengkap dan komprehensif dalam mengevaluasi suatu program. Tujuan penelitian ini adalah untuk melakukan evaluasi pada perkuliahan daring mata kuliah keterampilan menulis di Program Studi Pendidikan Bahasa dan Sastra Indonesia, IKIP PGRI Bojonegoro selama masa pandemi covid-19 dengan menggunakan model evaluasi CIPP. Penelitian ini merupakan penelitian kualitatif yang bersifat deskriptif evaluatif. Data pada penelitian ini bersifat primer dan sekunder. Data dikumpulkan dengan teknik wawancara, angket, dan dokumentasi. Instrumen penelitian ini menggunakan instrumen evalusi perkuliahan daring keterampilan menulis dengan menggunakan 21 soal dan menerapkan kriteria sangat tidak sesuai $(\leq 25 \%)$, tidak sesuai $(\geq$ $26 \%)$, sesuai $(\geq 51 \%)$, dan sangat sesuai $(\geq 76 \%)$. Data dianalisis dengan menggunakan metode content analysis. Hasil penelitian menunjukkan bahwa evaluasi perkuliahan daring keterampilan menulis selama masa pandemi covid-19 dengan model evaluasi CIPP pada aspek context didapatkan persentase sebesar 90\%. Pada aspek input didapatkan persentase sebesar $82 \%$. Pada aspek process didapatkan persentase sebesar $88 \%$. Pada aspek product didapatkan persentase sebesar 92\%. Persentase ini diambil dari rata-rata jumlah semua indikator pada masing-masing aspek. Penelitian ini menyimpulkan bahwa perkulian daring keterampilan menulis selama masa pandemi covid-19 dari semua aspek (context, input, process, product) sudah sangat sesuai.

Kata Kunci: evaluasi model CIPP, perkulihan daring, keterampilan menulis, pandemi covid-19 


\section{PENDAHULUAN}

Keterampilan Menulis merupakan mata kuliah wajib yang ada di Program Studi Pendidikan Bahasa dan Sastra Indonesia, IKIP PGRI Bojonegoro. Berdasarkan kurikulum program studi, mata kuliah keterampilan menulis berada di semester dua dengan kompetensi "Pemahaman dan pelatihan menulis sebagai salah satu aspek keterampilan bahasa untuk menunjang keterampilan berbahasa di sekolah".

Pada pembelajaran tahun akademik 2020-2021 dunia digemparkan dengan adanya keberadaan virus corona atau pandemi covid-19. Hal ini berpengaruh terhadap semua sektor kegiatan terkhusus sektor pendidikan. Sektor pendidikan formal dan nonformal, pendidikan dari jenjang pos PAUD hingga perguruan tinggi terkena dampak pandemi covid-19. Pemerintah melalui Kementerian Pendidikan dan Kebudayaan mengharuskan melakukan pembelajaran daring. Keharusan ini juga diterapkan oleh Program Studi Pendidikan bahasa dan Sastra Indonesia, IKIP PGRI Bojonegoro.

Mata kuliah keterampilan menulis di Program Studi Pendidikan bahasa dan Sastra Indonesia, IKIP PGRI Bojonegoro syarat dengan kemampuan dan keterampilan dalam hal tulis menulis, seperti, teknik menuangkan ide dalam tulisan, strategi memunculkan kohesi dan koherensi antar kalimat atau paragraf, teknik mengembangkan paragraf, teknik menulis cerita fiksi, dan teknik menulis karya ilmiah sehingga dosen perlu memberikan pendampingan yang inten kepada mahasiswa pada perkuliahan ini.

Mengingat pada perkuliahan tahun lalu, dosen pengampu mata kuliah keterampilan menulis benar-benar membimbing mahasiswa secara inten dengan berbagai strategi. Maka tidak heran pada akhir perkuliahan mahasiswa dapat menghasilkan sebuah produk paper di akhir perkuliahan keterampilan menulis. Kondisi perkuliahan tahun lalu sangatlah berbeda dengan kondisi perkuliahan tahun ini, sehingga apa yang diupayakan dosen pengampu mata kuliah pada perkulihan tahun lalu tidak bisa diimplementasikan pada perkuliahan tahun ini. Hal ini dikarenakan perkuliahan semester ini dilakukan secara daring. Berdasarkan kondisi perkuliahan daring mata kuliah keterampilan menulis di Program Studi Pendidikan bahasa dan Sastra Indonesia, IKIP PGRI Bojonegoro, maka penulis ingin melakukan evaluasi perkuliahan keterampilan menulis selama masa pandemi covid-19 dengan menggunakan model evaluasi yang tepat.

Evaluasi berasal dari bahasa Inggris evaluation, kata ini berasal dari kata value yang berarti nilai (Djuwita, 2012). Evaluasi dapat dimaknai sebagai proses sistematis, berkelanjutan, serta menyeluruh dalam rangka untuk mengendalikan, menjamin, serta menetapkan kualitas berbagai komponen pembelajaran (Asrul, 2014) sesuai target yang ingin dicapai (Sudjana, 2002) berdasarkan pada kemampuan intelektual (kognitif), kemampuan rasa, sikap, dan prilaku (afektif), serta kemampuan keterampilan (psikomotor) (Ismail, 2020).

Evalusi pembelajaran bertujaun untuk mengetahui efektivitas proses pembelajaran (Sukardi, 2009) yang mencakup keeping track (menulusuri dan melacak proses belajar), checking up (mengecek ketercapaian kemampuan), finding-out (mencari dan menemukan kekurangan), summing-up (menyimpulkan tingkat penguasaan) (Cittenden dalam Sutikno, 2013) serta memberikan feedback kepada guru sebagai dasar perbaikan proses pembelajaran (Saleh, 2000).

Evaluasi dapat dilaksanakan dengan menerapkan banyak model dan pendekatan. Banyaknya model dan mendekatan menurut Tayipnapis (2008) pelaksanaan evaluasi tetap bergantung pada misi, orientasi serta paham yang dianut evaluator. Fitzpatrick, Sanders, Worthen (2004) menyebutkan ada lima pendekatan dalam evaluasi, yaitu, pendekatan yang berorientasi 1) tujuan, 2) manajemen, 3) pemakai, 4) kepakaran, dan naturalistic-partisipan.

Kaufman dan Thomas (1980) menyebutkan bahwa ada delapan model evaluasi, yaitu 1) Goal Oriented Model yang dikembangkan oleh Ralph W. Tyler, 2) Goal Free Evaluation Model yang 
dikembangkan oleh Michael Scriven, 3) Formative-Sumative Evaluation Model yang dikembangkan oleh Michael Scriven, (4) Countenance Evaluation Model yang dikembangkan oleh R.E. Stake, (5) Responsive Evaluation Model yang dikembangkan oleh R.E. Stake, (6) CSEUCLA Evaluation Model yang menekankan pada "kapan" evaluasi dilaksanakan, (7) CIPP (Context - Input - Process-Product) Evaluation Model yang dikembangkan oleh Daniel L. Stufflebeam, dan (8) Discrepancy Model yang dikembangkan oleh Malcolm M. Provus.

Wholey (2010) mengembangan evaluasi logic model. Logic model merupakan model evaluasi yang dapat dipercaya dan mudah dipahami dalam memecahkan masalah yang telah diidentifikasi. Frechtling (2010) menambahkan bahwa evaluasi logic model memiliki tahapan evaluasi yaitu context, inputs, actvities, outputs, dan outcomes (short term dan long term).

Model evaluasi yang akan digunakan di kegiatan penelitian ini didasarkan pada fokus, tujuan, pertanyaan, dan rumusan masalah. Berpijak pada keempat hal tersebut maka penulis menggunakan model evaluasi yang dikembangkan oleh Daniel L. Stufflebeam, yaitu model CIPP. Penggunaan model evalusi CIPP dapat memberikan hasil evaluasi yang sangat akurat pada perkuliahan keterampilan menulis saat pandemi covid-19 karena mengevaluasi dari segi prapembelajara, saat pembelajaran, dan pascapembelajaran.

Konsep evaluasi model CIPP pertama kali dikenalkan oleh Stufflebeam pada tahun 1965. Stufflebeam melakukan evaluasi di ESEA (the Elementary and Secondary Education Act). Stufflebeam memberikan pandangan bahwa tujuan evaluasi adalah tidak hanya membuktikan tetapi dapat meningkatkan (Mahmudi, 2011). Model CIPP menurut Murwani (2006) memandang keberhasilan program pendidikan dipengaruhi oleh faktor: karakteristik dan lingkungan siswa, tujuan dan peralatan, prosedur dan mekanisme. Kekuatan CIPP (Context, Input, Process and Product) membantu evaluator memberikan pertanyaan penting ke evaluasi. Berikut bagan model CIPP.

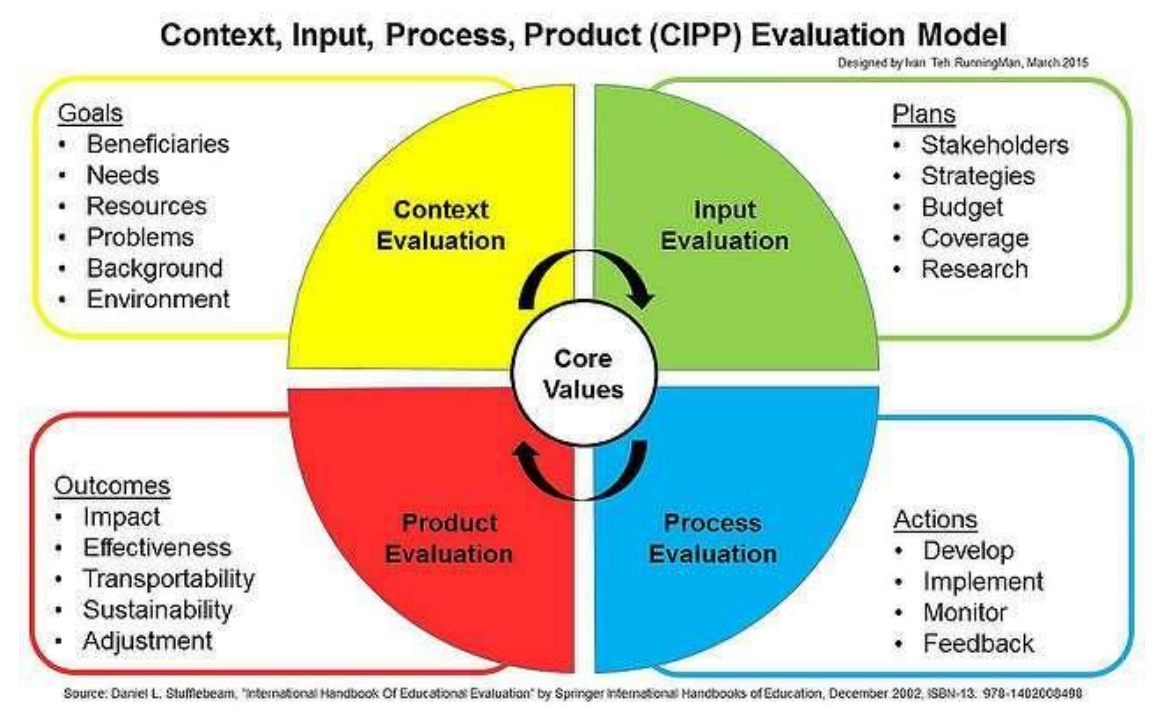

Gambar 1. Bagan model CIPP Asngari (2018)

Evaluasi konteks (context evaluation), to serve planning decision, evaluasi ini mencakup perencanan, kebutuhan program, dan tujuan program (Stufflebeam, 1971) untuk menilai masalah, kebutuhan, asset dan peluang (Supriyantoko, Jaya, Kurnia, dan Habiba, 2020) yang berhubungan dengan kondisi objektif (lingkungan program) yang akan dilaksanakan (Widoyoko, 2009). 
Evaluasi masukan (input evaluation), structuring decision (Stufflebeam, 1971), membantu mengambil keputusan dalam menentukan tujuan, prosedur kerja serta srategi apa yang akan digunakan dalam mencapai kebutuhan (Supriyantoko, Jaya, Kurnia, dan Habiba, 2020). Strategi alternatif perlu dipertimbangan dalam mencapai suatu program (Widoyoko, 2009).

Evaluasi proses (process evaluation), to serve implementing decision (Stufflebeam, 1971), mengindentifikasi suatu masalah dalam prosedur baik berupa aktivitas maupun kejadian (Widoyoko, 2009) yang bertujuan untuk memotret sejauh mana rencana telah diimpementasikan serta komponen apa saja yang perlu diperbaiki (Supriyantoko, Jaya, Kurnia, dan Habiba, 2020).

Evaluasi produk (product evaluation), to serve recycling decision, untuk menolong keputusan selanjutnya
(Stufflebeam, 1971) dalam menafsirkan dan mengukur hasil yang telah dicapai (Widoyoko, 2009) sesuai tujuan yang telah ditetapkan. Data pada kegiatan ini sebagai penentu apakah program dapat diteruskan, dimodifikasi atau bahkan dihentikan (Supriyantoko, Jaya, Kurnia, dan Habiba, 2020).

Karakteristik evaluasi model CIPP pada dasarnya terkait dengan empat macam penilaian, yaitu: 1) menilai prioritas dan tujuan lalu dibandingkan dengan peluang, masalah, dan kebutuhan yang tersedia, 2) menilai anggaran dan pelaksanaan lalu dibandingkan dengan target tujuan, 3) menilai keefektifan suatu program, 4) menilai keberhasilan suatu program dengan cara membandingkan efek dan hasil dengan target (Stufflebeam \& Coryn, 2014). Bentuk penilaian ini dapat didasarkan pada kategori tingkat keberhasilan seperti berikut.

Tabel 1. Kategori tingkat keberhasilan program dikembangkan oleh Jaya \& Ndeot (2019)

\begin{tabular}{cl}
\hline $\begin{array}{c}\text { Kategori Tingkat } \\
\text { Keberhasilan }\end{array}$ & \multicolumn{1}{c}{ Bentuk Rekomendasi } \\
\hline Rendah & Memperbaiki perencanaan dan strategi penyelenggaraan program \\
Sedang/tinggi & Meningkatkan kualitas penyelenggaran program \\
sangat tinggi & mengembangkan program \\
\hline
\end{tabular}

Evaluasi model CIPP memiliki kelebihan, dapat mengembangkan program, menyajikan informasi terkait pengambilan keputusan, adanya umpan balik dalam penyusunan program yang berkelanjutan, dan lebih komprehensif (Nurkholis, 2015). Kekomprehensifan model CIPP menurut Siregar (2021) dapat memberikan dasar yang lebih baik dalam mengambil kebijakan, keputusan, serta program selanjutnya.

Evaluasi model CIPP pernah dilakukan oleh Aprilia, Adnan, dan Aini (2021) untuk mengevaluasi penerapan kurikulum 2013 pada mata pelajaran bahasa Indonesia di Madrasah Aliyah Negeri. Syahrir, Supriyati, dan Fauzi (2021) menggunakan model CIPP untuk mengevaluasi kinerja dosen pada program PJJ (Pembelajaran Jarak Jauh). Penelitian Destrianto (2021) menggunaakan model
CIPP untuk mengevaluasi program gerakan literasi sekolah di sekolah dasar.

Berdasarkan pada penelitian tersebut, peneliti terdahulu belum pernah menggunakan model CIPP untuk mengevaluasi perkuliahan daring mata kuliah keterampilan menulis selama masa pandemi covid-19. Untuk itu, peneliti tertarik untuk melakukan evaluasi pada mata kuliah keterampilan menulis dengan menggunakan model evaluasi CIPP.

\section{METODE PENELITIAN}

Penelitian ini merupakan penelitian kualitatif yang bersifat deskriptif evaluatif dengan menggunakan model evaluasi CIPP (Context, Input, Process and Product). Penelitian evaluatif merupakan desain dan prosedur dalam mengumpulkan dan menganalisis data secara sistematis untuk menentukan nilai atau manfaat (worth) dari suatu praktik dalam dunia pendidikan 
(Gainau, 2021), menjawab pertanyaan, menguji, atau membuktikan sebuah hipotesis (Salim dan Haidir, 2019).

Data pada penelitian ini bersifat primer dan sekunder. Data primer diperoleh secara langsung dari responden. Responden dalam penelitian ini adalah mahasiswa dan dosen yang terlibat dalam mata kuliah keterampilan menulis di Program Studi Pendidikan Bahasa dan Sastra Indoensia, IKIP PGRI Bojonegoro. Data sekunder adalah data yang diperoleh secara tidak langsung dari sumbernya. Data sekunder dalam penelitian ini berupa RPS, produk yang dihasilkan mahasiswa, serta dokumen lain yang berkaitan dengan mata kuliah keterampilan menulis.

Data dikumpulkan dengan teknik wawancara, angket, dan dokumentasi.
Teknik wawancara pada penelitian ini menggunakan teknik wawancara semi terstruktur secara mendalam (indepht interview) dengan informan kunci adalah ketua program studi, dosen dan mahasiswa pada mata kuliah keterampilan menulis. Teknik angket dilakukan secara daring menggunakan google form untuk mengetahui pendapat dan tanggapan dari responden. Teknik dokumentasi dilakukan dengan cara mengumpulkan dokumen berupa RPS, nilai mahasiswa, dan produk mahasiswa.

$$
\text { Instrumen penelitian ini }
$$
menggunakan instrumen evalusi perkuliahan daring keterampilan menulis selama masa pandemi covid-19 dengan menggunakan model evaluasi CIPP seperti berikut.

Tabel 2. Instrumen evaluasi CIPP perkuliahan daring keterampilan menulis

\begin{tabular}{|c|c|c|c|}
\hline No. & Variabel/Indikator & Nilai & Kriteria \\
\hline $\mathbf{A}$ & Aspek Context & & \\
\hline 1 & tujuan pembelajaran (CPMK) & & \\
\hline 2 & kondisi lingkungan belajar & & \\
\hline 3 & kebutuhan dan karakteristik mahasiswa & & \\
\hline 4 & keterkaitan tujuan pembelajaran dengan pembelajaran daring & & \\
\hline 5 & $\begin{array}{l}\text { saling mendukung antara materi ajar dengan pembelajaran } \\
\text { daring }\end{array}$ & & \\
\hline B & Aspek Input & & \\
\hline 1 & pengetahuan awal mahasiswa & & \\
\hline 2 & kreatif dalam proses pembelajaran & & \\
\hline 3 & behavior mahasiswa & & \\
\hline 4 & konsentrasi pada materi perkuliahan & & \\
\hline 5 & sumber belajar & & \\
\hline 6 & sarana dan prasarana & & \\
\hline 7 & media pembelajaran & & \\
\hline $\mathbf{C}$ & Aspek Process & & \\
\hline 1 & kesesuaian rencana dengan pelaksanaan & & \\
\hline 2 & proses $\mathrm{KBM}$ daring berlangsung & & \\
\hline 3 & keberagaman model pembelajaran & & \\
\hline 4 & materi pembelajaraan sesuai dengan kurikulum & & \\
\hline D & Aspek Product & & \\
\hline 1 & $\begin{array}{l}\text { kemampuan yang diharapkan setelah mengikuti perkuliahan } \\
\text { daring }\end{array}$ & & \\
\hline 2 & ada respons positif dari wali mahasiswa & & \\
\hline 3 & ada respons positif dari dosen wali & & \\
\hline 4 & keterampilan menulis meningkat & & \\
\hline 5 & $\begin{array}{l}\text { model pembelajaran daring menjadi model bagi pelaksanaan } \\
\text { MBKM (Merdeka Belajar Kampus Merdeka) }\end{array}$ & & \\
\hline
\end{tabular}


Tabel 3. Range persentase dan kriteria kualitatif

\begin{tabular}{ccc}
\hline No. & Interval & Kriteria \\
\hline 1 & $0 \%<$ persentase $\leq 25 \%$ & sangat tidak sesuai \\
2 & $26 \%<$ persentase $\leq 50 \%$ & tidak sesuai \\
3 & $51 \%<$ persentase $\leq 75 \%$ & sesuai \\
4 & $76 \%<$ persentase $\leq 100 \%$ & sangat sesuai
\end{tabular}

Dikembangkan oleh Supriyantoko, Jaya, Kurnia, dan Habiba (2020)

Data dianalisis dengan menggunakan metode content analysis. Cara kerja metode ini dimulai dari 1) reduksi data, 2) penyajian data, dan 3) menarik simpulan (Miles dan Huberman, 2007).

\section{HASIL DAN PEMBAHASAN}

Berdasarkan hasil wawancara dan data angket di Program Studi Pendidikan Bahasa dan Sastra Indonesia, IKIP PGRI Bojonegoro yang mengimplementasikan pembelajaran daring selama masa pandemi covid-19 pada mata kuliah keterampilan menulis di mana angket yang sudah diisi oleh responden dimasukkan ke dalam tabel sesuai variabel dan indikator pada instrumen evaluasi CIPP dengan menggunakan deskriptif evaluatif didapatkan hasil sebagai berikut.

\section{Evaluasi Perkuliahan Daring Keterampilan Menulis selama Masa Pandemi Covid-19 ditinjau dari Aspek Context}

Pada aspek context didapatkan persentase sebesar $90 \%$ dari rata-rata jumlah semua indikator. Indikator tersebut mencakup 1) tujuan pembelajaran (CPMK), 2) kondisi lingkungan belajar, 3) kebutuhan dan karakteristik mahasiswa, 4) keterkaitan tujuan pembelajaran dengan pembelajaran daring, 5) saling mendukung antara materi ajar dengan pembelajaran daring.

Hasil evaluasi variabel konteks menunjukkan bahwa perkuliahan daring selama pandemi covid-19 pada mata kuliah keterampilan menulis memiliki kriteria sangat sesuai. Dosen mata kuliah keterampilan menulis membuat tujuan pembelajaran (CPMK) seperti berikut "Pada akhir perkuliahan mahasiswa diharapkan mempunyai kemampuan menuangkan gagasan/ide dalam karangan ilmiah, ilmiah populer, dan semi ilmiah".
CPMK ini sudah berada pada level 7, KKNI.

Kondisi lingkungan belajar sangat strategis dan sesuai dengan kemauan mahasiswa karena belajar dari rumah bisa dimana pun dan kapan pun. Mahasiswa hanya membutuhkan jaringan internet (paket data) dan sebagian besar sudah mendapat subsidi dari pemerintah, selain itu di balai desa-balai desa di lingkungan mahasiswa sudah menggunakan jaringan wifi sehingga kebutuhan paket data dapat terakomodasi. Karekteristik mahasiswa yang mengikuti mata kuliah keterampilan menulis dapat dikatakan sebagai generasi milenial karena hampir 98\% mereka lahir pada tahun 1990-an sehingaa semua ini sangat mendukung keberadaan pembelajaran daring selama pandemi covid-19.

Tujuan pembelajaran yang sudah disusun oleh dosen mata kuliah keterampilan menulis sangat sesuai dengan pembelajaran daring yang digunakan dosen. Hal ini nampak dari RPS yang disusun oleh dosen sudah disesuikan dengan kondisi pandemi covid-19. Materi ajar pun sudah dalam bentuk soft file dalam format power point dan siap diunggah pada sistem elearning mata kuliah keterampilan menulis sehingga materi ajar dengan pembelajaran daring saling berkesinambungan (saling mendukung).

\section{Evaluasi Perkuliahan Daring Keterampilan Menulis selama Masa Pandemi Covid-19 ditinjau dari Aspek Input \\ Pada aspek input didapatkan} persentase sebesar $82 \%$ dari rata-rata jumlah semua indikator. Indikator tersebut mencakup 1) pengetahuan awal mahasiswa, 2) kreatif dalam proses pembelajaran, 3) behavior mahasiswa, 4) konsentrasi pada 
materi perkuliahan, 5) sumber belajar, 6) sarana dan prasarana, dan 7) media pembelajaran.

Hasil evaluasi variabel input menunjukkan bahwa perkuliahan daring selama pandemi covid-19 pada mata kuliah keterampilan menulis memiliki kriteria sangat sesuai. Skemata mahasiswa dalam mengikuti perkulian keterampilan menulis sangat mendukung, ada Sebagian mahasiswa sudah pernah mendapat juara dalam bidang menulis, hal ini menandakan bahwa sejak awal skill mahasiswa dalam menulis sudah ada. Mahasiswa selama mengikuti perkuliah sangat kreatif. Pada tugas pertama, mahasiswa dapat menulis puisi dengan tema kearifan lokal yang ada di Kabupaten Bojonegoro. Puisi-puisi ini kemudian dibukukan menjadi sebuah antologi puisi.

Selama mengikuti perkulian daring, perilaku mahasiswa juga sangat berbudi dan beradab, mahasiswa selalu masuk ruang kuliah daring menggunakan aplikasi google meet tepat waktu, hanya ada beberapa mahasiswa yang terlambat karena jaringan kurang stabil. Hal ini disebabkan cuaca yang kurang mendukung. Ruang kuliah daring ini juga dimanfaatkan oleh mahasiswa untuk melakukan aktivitas yang lain, meskipun mahasiswa melakukan aktivitas yang lain, mahasiswa tetap fokus mengikuti perkulihan. Hal ini nampak dari antusiasme mahasiswa dalam memberikan pertanyaan saat waktu diskusi tiba. Selama perkuliahan daring mahasiswa juga sangat konsentrasi penuh terhadap materi yang disampaikan. Hal ini nampak dari jawaban mahasiswa saat diberikan pertanyaan langsung oleh dosen. Namun, ada beberapa mahasiswa yang kurang tepat dalam menjawab. Kekurangtepatan ini kemudian dapat diperbaiki oleh teman yang bisa. Dalam pembelajaran keterampilan menuli secara daring, peran dosen sama, yaitu sebagai fasilitator pembelajaran. Pembelajaran tetap berpusat pada mahasiswa (student center).

Dosen memberikan materi dalam bentuk PPT sebelum perkulian di mulai, dosen juga memberikan laman untuk mencari sumber referensi lain, misalnya melalui laman https://scholar.google.com/ atau https://doaj.org/ atau https://www.sciencedirect.com/browse/jour nals-and-books untuk mencari materi tambahan dalam bentuk artikel nasional dan internasional. Untuk sumber tambahan dalam bentuk buku nasional dan internasional, dosen memberikan laman https://books.google.co.id/ atau http://en.bookfi.net/ atau http://libgen.rs/ atau

https://press.anu.edu.au/publications/newreleases.

Sarana dan prasarana yang digunakan adalah aplikasi google meet untuk pembelajaran tatap muka. Untuk mengumpulkan tugas, mengerjakan soal tes, dan materi-materi, dosen membuat kelas daring menggunakan aplikasi schoology. Kelas daring mata kuliah keterampilan menulis dapat diihat pada gambar berikut.

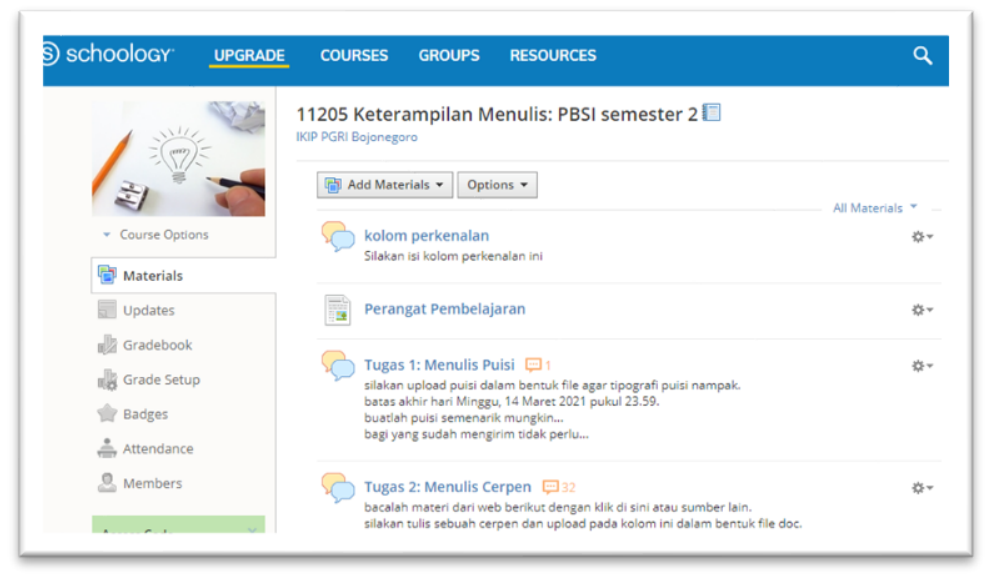

Gambar 2. Kelas daring asinkronus mata kuliah keterampian menuls 
Aplikasi google meet dan aplikasi shoology merupakan dua media utama dalam menunjang keberhasilan perkulian daring mata kuliah keterampilan menulis pada masa pandemi covid-19.

\section{Evaluasi Perkuliahan Daring Keterampilan Menulis selama Masa Pandemi Covid-19 ditinjau dari Aspek Process}

Pada aspek process didapatkan persentase sebesar $88 \%$ dari rata-rata jumlah semua indikator. Indikator tersebut mencakup 1) kesesuaian rencana dengan pelaksanaan, 2) proses KBM daring berlangsung, 3) keberagaman model pembelajaran, 4) materi pembelajaraan sesuai dengan kurikulum.

Rencana Pembelajaran Semester (RPS) yang dibuat dosen sudah disesuikan dengan kondisi pandemi covid-19. Dosen sudah mensetting Rencana Pembelajaran Semester (RPS) dengan mengimplementasikan pembelajaran sinkronus dan asinkronus. Kedua model pembelajaran ini benar-benar diimplementasikan dosen agar CPMK yang dibuat benar-benar terukur dan tuntas. Hasanudin, Supriyanto, \& Pristiwati (2020) menambahkan bahwa Pembelajaran jarak jauh yang dapat diterapkan di sekolahsekolah salah satunya adalah dengan mengelaborasi model pembelajaran dan media pembelajaran.

Pada proses pembelajaran sinkronus dosen menggunakan aplikasi google meet. Aplikasi ini sangat membantu dosen untuk menyampikan materi perkuliahan daring. Google meet dipilih karena sangat mudah digunakan dan tidak boros kuota internet (berdasarkan hasil wawancara dengan beberapa mahasiswa). Mahasiswa sering aktif mengikuti perkuliahan dengan google meet, meskipun mereka kurang enak badan, mereka izin mematian video karena menyimak sambil berbaring. Hal ini dilakukan mahasiswa atas persetujuan dosen pengampu sebelumnya. Selain itu, ada beberapa mahasiswa yang mematikan kamera dengan alasan lain, misal sedang diwarung kopi. Alasan warung kopi dipilih karena jaringan wifi di warung kopi sangat lancar.
Pada proses pembelajaran asinkornus dosen mengunggah semua materi pada kelas daring keterampilan menulis menggunakan aplikasi schoology. Aplikasi ini sebagai media komunikasi dosen dengan mahasiswa. Pada kelas daring ini, dosen selalu membuat kolom diskusi pada setiap babnya, fungsi kolom diskusi adalah untuk memberikan ruang antara mahasiswa dengan mahasiswa lain bahkan dengan dosen pengampu untuk memberikan feedback terhadap jawaban mahasiswa yang kurang pas. Kolom diskusi ini juga digunakan sebagai media bertanya mahasiswa jika mahasiswa mengalami kendala atau kesulitan dalam mempelajari materi.

Pengimplementasian pembelajaran sinkronus dan asinkronus merupakan dua model pembelajaran yang efektif diimplementasikan saat pandemi covid-19 sehingga materi-materi perkulian keterampilan menulis tetap tersampaikan kepada mahasiswa. Materi-materi yang disusun oleh dosen meskipun dalam kondisi pandemi covid-19 sudah sama dengan kurikulum yang dipakai oleh Program Studi Pendidikan Bahasa dan Sastra Indonesia, IKIP PGRI Bojonegoro.

\section{Evaluasi Perkuliahan Daring Keterampilan Menulis selama Masa Pandemi Covid-19 ditinjau dari Aspek Product}

Pada aspek product didapatkan persentase sebesar $92 \%$ dari rata-rata jumlah semua indikator. Indikator tersebut mencakup 1) kemampuan yang diharapkan setelah mengikuti perkuliahan daring, 2) ada respons positif dari wali mahasiswa, 3) ada respons positif dari dosen wali, 4) keterampilan menulis meningkat, 5) model pembelajaran daring menjadi model bagi pelaksanaan MBKM (Merdeka Belajar Kampus Merdeka).

Pada perangkat pembelajaran, dosen menulis bahwa setelah mengikuti mata kuliah keterampilan secara daring diharapkan mahasiswa mempunyai kemampuan menuangkan gagasan/ide dalam karangan ilmiah, ilmiah populer, dan semi ilmiah. Pada kenyataannya pembelajaran daring selama pandemi 
covid-19 membuat mahasiswa tetap dapat menuangkan gagasan/ide ke dalam bentuk karangan. Kondisi ini mendapat respons positif oleh wali mahasiswa. Meskipun anak mereka sudah mahasiswa, tetapi saat di rumah tetap aktif mengikuti perkuliahan daring dan mengerjakan tugas secara daring pula. Dosen wali pun memberikan respons positif. Saat di wawancara di ruang dosen, salah satu dosen wali dari mahasiswa tingkat 2 memberikan apresiasi bahwa mahasiswa tetap berkarya dan menghasilkan produk walaupun belajar secara daring. Alhasil, keterampilan mahasiswa setelah mengikuti perkuliahan daring mata kuliah keterampilan menulis meningkat. Peningkatan ini dapat dilihat dari nilai-nilai tugas dan tes keterampilan menulis.

Peningkatan keterampilan menulis mahasiswa ini didukung oleh model pembelajaran sinkronus dan asinkronus sehingga kedua model ini dapat dijadikan sebagai acuan model bagi pelaksanaan MBKM (Merdeka belajar Kampus Merdeka). Model pembelajaran sinkronus dan asinkronus dengan memanfaatkan aplikasi google meet dan aplikasi schoology sangat membantu pembelajaran daring saat pandemi covid-19 sehingga dapat disimpulan bahwa kedua aplikasi ini juga sangat tepat jika diimplementasikan pada program studi yang sudah menyelenggarakan program kampus merdeka.

Pemanfaatan aplikasi schoology menurut Hasanudin (2020) sebagai 1) penunjang dalam pembelajaran abad 21,2 ) adanya perpaduan jejaring sosial dan $e$ learning, 3) sangat mudah digunakan. Aplikasi schoology juga dapat diimplementasikan pada model pembelajaran SSCS pada matakuliah sintaksis (Saddhono, Hasanudin, \& Fitrianingsih, 2021). Aplikasi schoology juga dapat dikolaborasi dengan model flipped classroom untuk mengetahui keterampilan menceritakan kembali teks ulasan siswa (Rosyida, Kristiana, \& Hasanudin, 2020).

Evaluasi model CIPP pernah dilakukan oleh Oktaria \& Hadiwinarto (2021) untuk mengevaluasi kesiapan mahasiswa, proses penggunaan e-learning, faktor penghambat e-learning pada proses pembelajaran. Anggara (2021) untuk mengetahui tingkat keefektifan pembelajaran online selama pandemi covid19. Hidayat (2021) untuk mengevaluasi perkuliahan daring selama pandemi covid19 pada progam studi sejarah. Argi, Pelana, \& Setiakarnawijaya (2021) untuk mengevaluasi tingkat efektivitas latihan fisik dengan pembelajaran virtual selama pandemi covid-19.

\section{SIMPULAN}

Evaluasi perkuliahan daring keterampilan menulis selama masa pandemi covid-19 dengan model evaluasi CIPP dapat disimpulkan bahwa, pada aspek context didapatkan persentase sebesar $90 \%$ dari rata-rata jumlah semua indikator. Pada aspek input didapatkan persentase sebesar $82 \%$ dari rata-rata jumlah semua indikator. Pada aspek process didapatkan persentase sebesar $88 \%$ dari rata-rata jumlah semua indikator. Pada aspek product didapatkan persentase sebesar $92 \%$ dari rata-rata jumlah semua indikator. Hal ini dapat dikatakan bahwa perkulian daring keterampilan menulis selama masa pandemi covid-19 dari semua aspek (context, input, process, product) sudah sangat sesuai.

\section{DAFTAR RUJUKAN}

Anggara, F. (2021). Evaluasi tingkat pembelajaran pendidikan jasmani, olahraga \& kesehatan pada masa pandemi covid-19. Jurnal Ilmiah Bina Edukasi, 1(1), 37-45. Retrieved from

http://jurnal.umika.ac.id/index.php/ju rnal edukasi/article/view/158.

Aprilia, W., Adnan, \& Aini, R. Q. (2021). Evaluasi implementasi kurikulum 2013 pada mata pelajaran bahasa Indonesia di Madrasah Aliyah Negeri 2 sumbawa tahun pelajaran 2020. Jurnal PELITA (Pembelajaran, Linguistik, \& Sastra), 1(1), 16-22. Retrieved from http://jurnalfkip.universitassamawa.ac.id/index.php/PELITA/arti cle/view/13. 
Argi, A., Pelana, R., \& Setiakarnawijaya, Y. (2021). Evaluation of learning physical education in the covid-19 pandemic. Gladi: Jurnal Ilmu Keolahragaan, 12(01), 55-61. Retrieved from http://journal.unj.ac.id/unj/index.php/ gjik/article/download/17720/10355.

Asngari. H. (2018). CIPP (Context, Input, Process, Product). Retrieved from https://docplayer.info/72917861Cipp-context-input-process-productoleh-hasim-asngari-nim.html.

Asrul, dkk. (2014). Evaluasi Pembelajaran. Medan, Indonesai: Ciptapustaka Media.

Destrianto, K. (2021). Evaluasi Program Gerakan Literasi Sekolah di SD Kristen 04 Eben Haezer. Scholaria: Jurnal Pendidikan dan Kebudayaan, 11(2), 133-139. Retrieved from https://ejournal.uksw.edu/scholaria/ar ticle/view/3505.

Djuwita, W. (2012). Evaluasi pembelajaran. Lombok Barat, Indonesia: El Hikam Press Lombok.

Fitzpatrick, J. L. Sanders, J. R., Worthen, B. R. (2004). Program Evaluation Alternative Approaches and Practical Guidelines. New York: Pearson Education.

Frechtling, J. A. (2010). The 2010 UserFriendly Handbook for Project Evaluation $t t$ : Division of Research and Learning in Formal and Informal Settings National Science Foundation.

Gainau, M. B. (2021). Pengantar Metode penelitian. Yogyakarta, Indonesia: PT Kanisius.

Hasanudin, C. (2020, May). E-Learning Schoology: Bagaimana Peran dan Implementasi pada Pembelajaran Masa Pandemi covid-19?. dalam Prosiding Seminar Nasional
Hardiknas, 1, 85-90. Retrieved from http://proceedings.ideaspublishing.co .id/index.php/hardiknas/article/view/ $\underline{13 / 13}$.

Hasanudin, C., Supriyanto, R. T., \& Pristiwati, R. (2020). Elaborasi model pembelajaran flipped classroom dan google classroom sebagai bentuk self-development siswa mengikuti pembelajaran bahasa indonesia di era Adaptasi Kebiasaan Baru (AKB). Intelegensia: Jurnal Pendidikan Islam, 8(2), 8597. Retrieved from https://ejournal.unisnu.ac.id/JI/article /view/1414.

Hidayat, B. (2021). Analisis pelaksanaan perkuliahan pendidikan IPS dengan memanfaatkan e-learning berbasis SPADA UM Metro. HISTORIA: Jurnal Program Studi Pendidikan Sejarah, 9(2). Retrieved from http://fkip.ummetro.ac.id/journal/ind ex.php/sejarah/article/view/3646.

Ismail. M. I. (2020). Evaluasi pembelajaran: Konsep dasar, prinsip, teknik, dan prosedur. Depok, Indonesia: PR RajaGrafindo Persada.

Jaya, P. R. P., \& Ndeot, F. (2019). Penerapan model evaluasi CIPP dalam mengevaluasi program layanan PAUD holistik integratif. PERNIK: Jurnal Pendidikan Anak Usia Dini, 1(01), 10-25.

Doi http://dx.doi.org/10.31851/pernik.v1i 01.2622 .

Kaufma, R. dan Thomas, S. (1980). Evaluation Without Fear. New York: New Viewpoints Division, Franklin Watts, Inc.

Mahmudi, I. (2011). CIPP: Suatu Model Evaluasi Program Pendidikan. AtTa'dib, 6(1), 111-125. Doi http://dx.doi.org/10.21111/attadib.v6i1.551. 
Miles, M. B. dan Huberman, A. M. (2007). Analisis Data Kualitatif: Buku Sumber Tentang Metode-Metode Baru. Terjemahan Tjetjep Rohendi Rohidi. Jakarta: Universitas Indonesia Press.

Murwani, S. (2006). Evaluasi Pendidikan. Jakarta, Indonesia: Uhamka Press.

Nurkholis. (2015). Santri Wajib Belajar. Purwokerto: Stain Press.

Oktaria, S. D., \& Hadiwinarto, H. (2021). Evaluasi penerapan pembelajaran online menggunakan e-learning di masa pandemi covid-19 pada tingkat perguruan tinggi. Ad-Man-Pend: Jurnal Administrasi Manajemen Pendidikan, 3(2), 24-29. Retrieved from https://jurnal.umpalembang.ac.id/jaeducation/article/v iew/3055.

Rosyida, F., Kristiana, Y., \& Hasanudin, C. (2020). Analisis keterampilan menceritakan kembali teks ulasan dengan kolaborasi metode flipped classroom dan aplikasi schoology. Jurnalistrendi: Jurnal Linguistik, Sastra, dan Pendidikan, 5(2), 86-96. Doi https://doi.org/10.51673/jurnalistrend i.v5i2.303.

Saddhono, K., Hasanudin, C., \& Fitrianingsih, A. (2021). The Analysis of "Search Solve Create Share" Learning Model Using Schoology Apps: Indonesian Syntax Learning. Psychology and Education Journal, 58(2), 4702-4710. Doi https://doi.org/10.17762/pae.v58i2.28 $\underline{57}$.

Saleh, A. R. (2000). Pendidikan Agama dan Keagamaan Visi, Misi dan aksi. Jakarta, Indonesia: Gemawindu Pancaperkasa.

Salim dan Haidir (2019). Penelitian pendidikan: Metode, pendekatan, dan jenis. Edisi pertama. Jakarta, Indonesia: Kencana.
Siregar, K. A. A. (2021). Evaluasi model CIPP (Context, Input, Process, Product). Dalam Mawardi Lubis (ed.), Evaluasi program dan kelembagaan pendidikan Islam (hlm. 163-174). Bengkulu, Indonesia: CV. Zigie Utama.

Stufflebeam, D. L. (1971). Evaluation as enlightment for decisión making. Columbus, Ohio: Ohio State University.

Stufflebeam, D.L., Coryn, Chris L. S. (2014). Evaluation: Theory, Models, \& Application (Second Edition). San Fransisco: Jossey-Bass.

Sudjana, N. (2002). Dasar-dasar proses belajar mengajar. Bandung, Indonesia: Sinar Baru.

Sukardi. (2009). Evaluasi pendidikan. medan, Indonesia: PT Bumi Aksara.

Supriyantoko, I., Jaya, A., Kurnia, V., \& Habiba, P. G. S. (2020). Evaluasi implementasi kebijakan teaching factory dengan model evaluasi CIPP di SMK Negeri DKI Jakarta. Journal of Vocational and Technical Education (JVTE), 2(2), 1-10. Retrieved from https://journal.unesa.ac.id/index.php/ JVTE/article/view/10869/4557.

Sutikno. (2013). Belajar dan pembelajaran. Lombok, Indonesia: Holistica.

Syahrir, Supriyati, Y., \& Fauzi, A. (2021). Evaluasi dampak program pendidikan jarak jauh (pjj) melalui model CIPP pada kinerja dosen aspek pembelajaran pada masa pendemi covid 19. Jurnal Ilmiah Mandala Education, 7(1). 144-150. Retrieved from http://ejournal.mandalanursa.org/inde x.php/JIME/article/view/1716.

Tayipnapis, F. Y. (2008). Evaluasi Program dan Instrumen Evvaluasi untuk Program Pendidikan dan 
38 JURNAL PENDIDIKAN EDUTAMA, Vol.8, No.2 Juli 2021

Pelatihan. Jakarta, Indonesia: Rineka Cipta.

Wholey, J. S. (2010). Handbook of Practical Program Evaluation. San Fransisco: Jossey-Bass.
Widoyoko, E. P. (2009). Evaluasi program pembelajaran. Indonesia: Pustaka Pelajar 238. 